\title{
Experience with Ommaya Reservoir in 120 Consecutive Patients with Meningeal Malignancy
}

\author{
R.G. Perrin, M. Lishner, A. Guha, J. Curtis, R. Feld and H. Messner
}

\begin{abstract}
The Ommaya Reservoir plays an important role in a select group of neuro-oncology patients with meningeal malignancy. The benefits derived must be balanced against potential complications associated with insertion and use of the apparatus. Side effects may be minimized by careful attention to patient selection, pre-operative CAT scan (or MRI), precise surgical technique, perioperative prophylactic antibiotics and meticulous procedure during use of the reservoir.

RÉSUMÉ: Expérience avec le réservoir d'ommaya chez 120 patients consécutifs atteints de néoplasie méningée Le réservoir d'Ommaya joue un rôle important en neuro-oncologie chez un groupe sélectionné de patients atteints de néoplasie méningée. Les bénéfices escomptés doivent être pesés en regard des complications possibles associées avec la mise en place et l'utilisation de ce dispositif. Les effets secondaires peuvent être minimisés par un choix judicieux des patients, un CAT scan pré-opératoire (ou MRI), une technique chirurgicale précise, une antibiothérapie péri-opératoire prophylactique et une procédure méticuleuse pendant l'utilisation du réservoir.
\end{abstract}

Can. J. Neurol. Sci. 1990; 17:190.192

A subcutaneous reservoir and pump (Ommaya Reservoir), designed to provide sterile access to ventricular CSF was described in 1963.1 This device was initially introduced as a means to deliver antibiotics intrathecally. The technique has subsequently been applied for intrathecal chemotherapy administration, intraventricular Morphine infusions, CSF sampling and fluid aspiration from the ventricular system or implanted cystic cavities.

This report summarizes our experience with insertion of a CSF reservoir-pump system in 120 consecutive patients for the treatment of meningeal malignancy.

\section{METHOD}

Patients who are to receive intrathecal chemotherapy for meningeal malignancy are considered for Ommaya reservoir insertion if there are no contraindications to the procedure. A preoperative CAT scan (or MRI) is essential to establish ventricular size and figuration, and to rule out the presence of tumour at the intended burr hole site, or along the ventricular access trajectory.

Surgery is performed with the patient supine on the operating table, the head positioned brow up and cradled on a "doughnut" ring. Scalp surface markings for the sagittal and coronal suture lines are established and the burr hole site is determined at a point just anterior to the coronal suture line and $2.5 \mathrm{~cm}$ to the right of the midline. A curvilinear skin incision is planned to create a scalp flap which will cover the implanted reservoir (Figure 1). The site is then infiltrated with approximately $8 \mathrm{~mL}$ of $2 \%$ Xylocaine with Epinephrine. The scalp is scrubbed and draped and the skull is exposed. The burr hole is created and the dura is coagulated in cruciate fashion and incised. The piaarachnoid is breached with bipolar cautery and a brain needle is then passed into the right lateral ventricle (aiming for the bridge of the patient's nose in the coronal plane and the contralateral external auditory meatus in the sagittal plane). A sample of ventricular CSF is collected and sent for cytology. The brain needle is withdrawn and Silastic ventricular cannula, cut to size ( 7 to $7.5 \mathrm{~cm}$ ) is passed along the brain needle trace. The ventricular cannula is connected to the round-bottomed reservoir which rests snugly in the burr hole site. Once satisfied that the system is patent, the wound is closed in layers.

All patients receive perioperative prophylactic antibiotics (Cefazolin Sodium, $1 \mathrm{gm} \mathrm{q} 8 \mathrm{~h}$ for 24 hours beginning at surgery).

This series includes 56 men and 64 women ranging in age from 11 to 79 years (with a mean of 43 years).

The underlying primary malignancies are listed in Table 1.

\section{COMPlications}

Eleven patients (nine percent) suffered complications related to insertion of the apparatus. Malposition of the ventricular catheter occurred in one case, early in the series. This patient's post-operative course was characterized by deteriorating level of consciousness and she died five days following reservoir insertion. Malfunction of the device occurred in five patients. Revision was carried out in three cases and the non-functioning 
Table 1: Meningeal Malignancy

\begin{tabular}{lr}
\hline Primary Tumour & Patients \\
\hline Acute lymphoblastic leukaemia & 30 \\
Acute myelogenous leukaemia & 14 \\
Chronic lymphocytic leukaemia & 3 \\
Chronic myelocytic leukaemia & 2 \\
Lymphoma & 39 \\
Carcinoma & 32 \\
& 120
\end{tabular}

apparatus was left in place in two cases. Subdural hygroma occurred in two patients and a subdural haematoma in one patient - in each case, the surface collection was evacuated with resolution of symptoms. Mild intraventricular bleeding occurred in two patients (necessitating removal of the apparatus in one case). The blood resorbed spontaneously without illeffect in both of these patients.

Infectious complications occurred in twelve patients (with recurrent CSF infections in three cases). One patient died of staphylococcus aureus septicaemia which occurred following revision of the ventricular catheter. Organisms cultured from the remaining cases included staph epidermidis,(1) diphtheroids,(2) propeono bacterium acnes,(2) staph homonyous (2) and candida parapsilosis.(2) The infections were successfully treated with

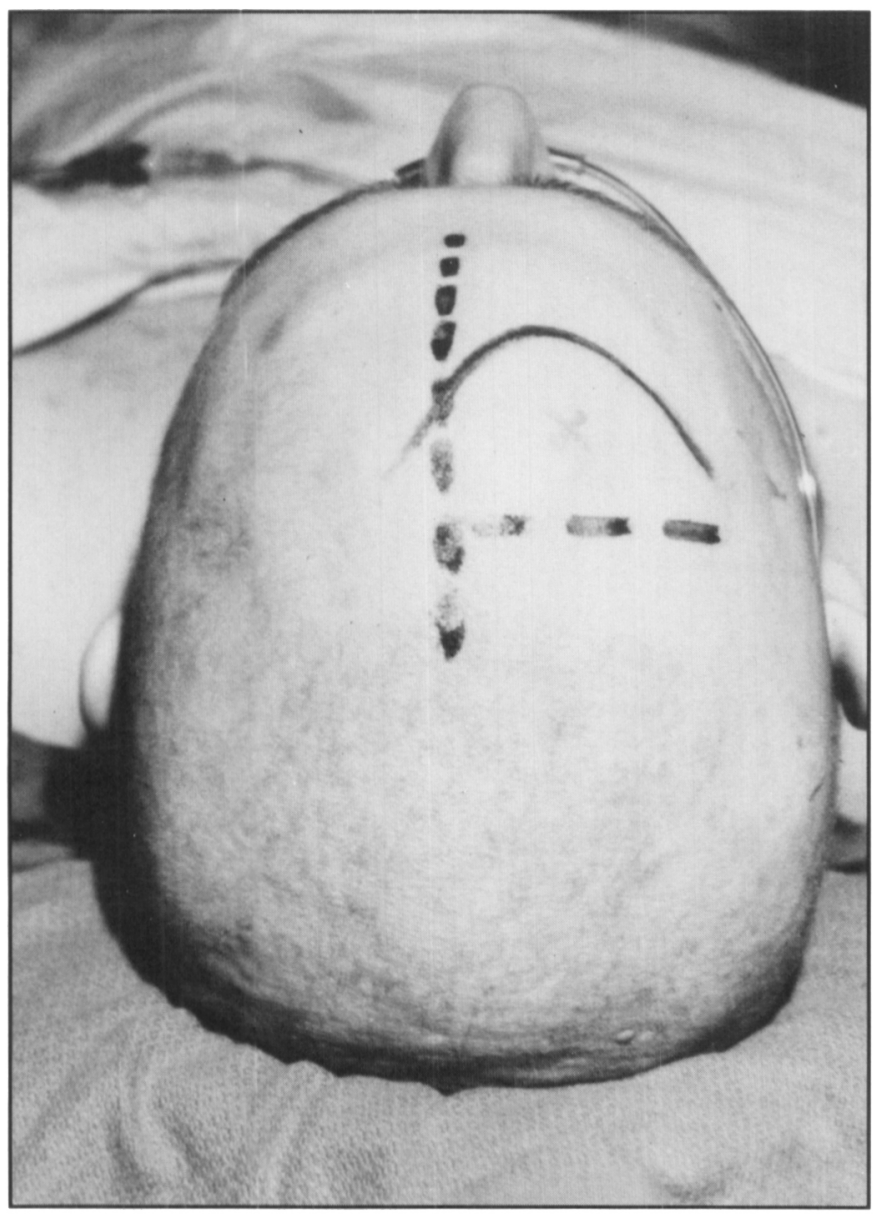

Figure I - Scalp flat incision. systemic antibiotics in eleven patients, and with removal of the implanted apparatus in four cases.

There were no toxic complications related to chemotherapy administration documented in this series.

\section{Discussion}

The Ommaya Reservoir provides a convenient and well-tolerated means for the repeated delivery of intrathecal chemotherapy and sampling of ventricular CSF. An alternative method, using serial lumbar punctures is painful and has been associated with complications including scarring and fibrosis of the subarachnoid space. The Ommaya Reservoir provides a reliable route for intraventricular drug delivery and CSF distribution which is superior to that achieved through lumbar puncture. ${ }^{3}$

The early experience with this technique involved insertion of the apparatus through a posterior parietal or occipital burr hole. 1.4-6 More recently, a right frontal approach has become standard in an effort to eliminate inadvertant damage to the internal capsule and to provide an easier path to the ventricular system.4,7 The use of a round-bottomed convertable shunt pump-reservoir which rests snugly in the burr hole helps to prevent displacement of the apparatus. A scalp flap which covers the implanted reservoir permits early use of the apparatus by percutaneous reservoir puncture through scalp remote from the skin incision.

Insertion and use of the CSF reservoir and pump apparatus is not innocuous. Reported mortality ranges from $0.5-8.3 \% .5 .8$ Furthermore, a wide range of complications has been encountered (Table 2).

Technical complications (related to insertion of the device) have been reported in up to 28 per cent of some series.4. 6-10 Malfunction of the apparatus is the most commonly reported technical problem. While the failure to function is due in some

Table 2: Complications

\begin{tabular}{lcccc}
\hline Authors & Technical & Infection & Toxic & Mortality \\
$\begin{array}{l}\text { Ratcheson \& } \\
\text { Ommaya } \\
\text { (1968) }\end{array}$ & $17 / 60(28 \%)$ & $12 / 60(20 \%)$ & $1 / 60(1.7 \%)$ & \\
$\begin{array}{l}\text { Galicich } \\
\text { \& Guido } \\
\text { (1974) }\end{array}$ & $9 / 45(20 \%)$ & $4 / 45(9 \%)$ & - & \\
$\begin{array}{l}\text { Gribbin } \\
\text { et al } \\
\text { (1977) }\end{array}$ & $2 / 8(25 \%)$ & $4 / 8(50 \%)$ & $1 / 8(12.5 \%)$ & \\
$\begin{array}{l}\text { Bleyer \& } \\
\text { Poplack } \\
\text { (1979) }\end{array}$ & $1 / 10(10 \%)$ & $1 / 10(10 \%)$ & $2 / 10(20 \%)$ & \\
$\begin{array}{l}\text { Jacobs } \\
\text { et al } \\
\text { (1981) }\end{array}$ & $4 / 24(17 \%)$ & - & $2 / 24(8.3 \%)$ & $2 / 24(8.3 \%)$ \\
$\begin{array}{l}\text { Obens } \\
\text { et al } \\
\text { (1985) }\end{array}$ & $25 / 387(6.5 \%)$ & $19 / 387(4.9 \%)$ & $10.387(2.6 \%)$ & $2 / 387(0.5 \%)$ \\
$\begin{array}{l}\text { Machado } \\
\text { et al } \\
\text { (1985) }\end{array}$ & $9 / 60(15 \%)$ & - & & \\
$\begin{array}{l}\text { Present } \\
\text { Study }\end{array}$ & $11 / 120(9 \%)$ & $15 / 120(12.5 \%)$ & - & $2 / 120(1.6 \%)$ \\
\hline
\end{tabular}


cases to malposition of the ventricular catheter at the time of insertion, it has been suggested that migration of the intraventricular catheter tip may occur due to alterations in CSF dynamics associated with use of the apparatus (i.e., forceful aspiration of CSF). 2,4.7 Malposition of the catheter tip has been associated with significant patient morbidity and mortality. 5,10

Infectious complications have been reported in up to $50 \mathrm{per}$ cent of cases. $4,6.10$ The most common problem relates to CSF infection by skin contaminants (particularly staph epidermidis). $3,4,10,11$ The lack of correlation between frequency of reservoir use and incidence of infectious complications reported by some authors has been interpreted to indicate that CSF contamination may be the result of a single careless reservoir access. ${ }^{4}$ While local cellulitis following surgical insertion usually necessitates removal of the reservoir, CSF bacterial contamination related to use of the reservoir can be successfully managed without removal of the apparatus. ${ }^{11}$

Toxic complications have been reported in up to twenty per cent of patients. ${ }^{9}$ Autopsy studies have usually confirmed the presence of necrotizing leuko-encephalopathy caused by the chemotherapeutic agent.

Unusual complications associated with the Ommaya Reservoir have included tumour growth about the ventricular cannula. $^{2}$

\section{REFERENCES}

1. Ommaya AK. Subcutaneous reservoir and pump for sterile access to ventricular CSF. Neurol 1985; 35: 1274-1278.
2. Bleyer WA, Pizzo PA, Spence AM, et al. The Ommaya reservoir: newly recognized complications and recommendations for insertion and use. Cancer 1978; 41: 2431-2437.

3. Reiselbach RE, Dichino G, Freireich EJ. Subarachnoid distribution of drugs after lumbar injection. New England J Med 1962; 267: 1273.

4. Galicich JJ, Guido LJ. Ommaya device in carcinomatous and leukaemic meningitis: surgical experience in 45 cases. Surg Clin N Am 1974; 54: 915-922.

5. Jacobs A, Clifford P, Kay HEM. The Ommaya reservoir in chemotherapy for malignant disease in the CNS. Clin Oncol 1981; 7: 123-129.

6. Ratcheson RA, Ommaya AK. Experience with the subcutaneous cerebrospinal fluid reservoir. New England J Med 1968; 279: 1025-1031.

7. Machado M, Salcman M, Kaplan RS, et al. Expanded role of the cerebrospinal fluid reservoir in neuro-oncology: indications, causes of revision, and complications. Neurosurgery 1985; 17: 600-603.

8. Obens EAMT, Leavens ME, Beal JN, et al. Ommaya reservoirs in 387 cancer patients: a 15-year experience. Neurology 1985; 35: 1274-1278.

9. Bleyer WA, Poplack DG. Intraventricular versus intralumbar methotrexate for central nervous system leukaemia: prolonged remission with Ommaya reservoir. Medical and Paediatric Oncology 1979; 6: 207-213.

10. Gribbin JA, Hardisdy RM, Chessells JM. Long-term control of central nervous system leukaemia. Arch Dis Childhood 1977; 52: 673-678.

11. Connors JM. Cure of Ommaya reservoir associated stalphylococcus epideridis ventriculitis with a simple regimen of vancomycin and rifampin without reservoir removal. Med and Paed Oncol 1982; 10: $549-552$. 